Supplement of Atmos. Chem. Phys. Discuss., 14, 13301-13330, 2014

http://www.atmos-chem-phys-discuss.net/acpd-14-13301-2014/

doi:10.5194/acpd-14-13301-2014-supplement

(C) Author(s) 2014. CC Attribution 3.0 License.

(c) (1)

\title{
A modelling study of moisture redistribution by thin cirrus clouds
}

T. Dinh et al.

Correspondence to: T. Dinh (tdinh@princeton.edu) 
This document contains the supplemental animations for "A modelling study of moisture redistribution by thin cirrus clouds." The animations shown here are for the four numerical experiments: no-rad (no-radiation) and all-phys (all-physics) simulations in the dry and moist scenarios. Details of the model configurations of these numerical experiments are provided in the article. The animations can be played if the document is opened with Adobe Reader. 


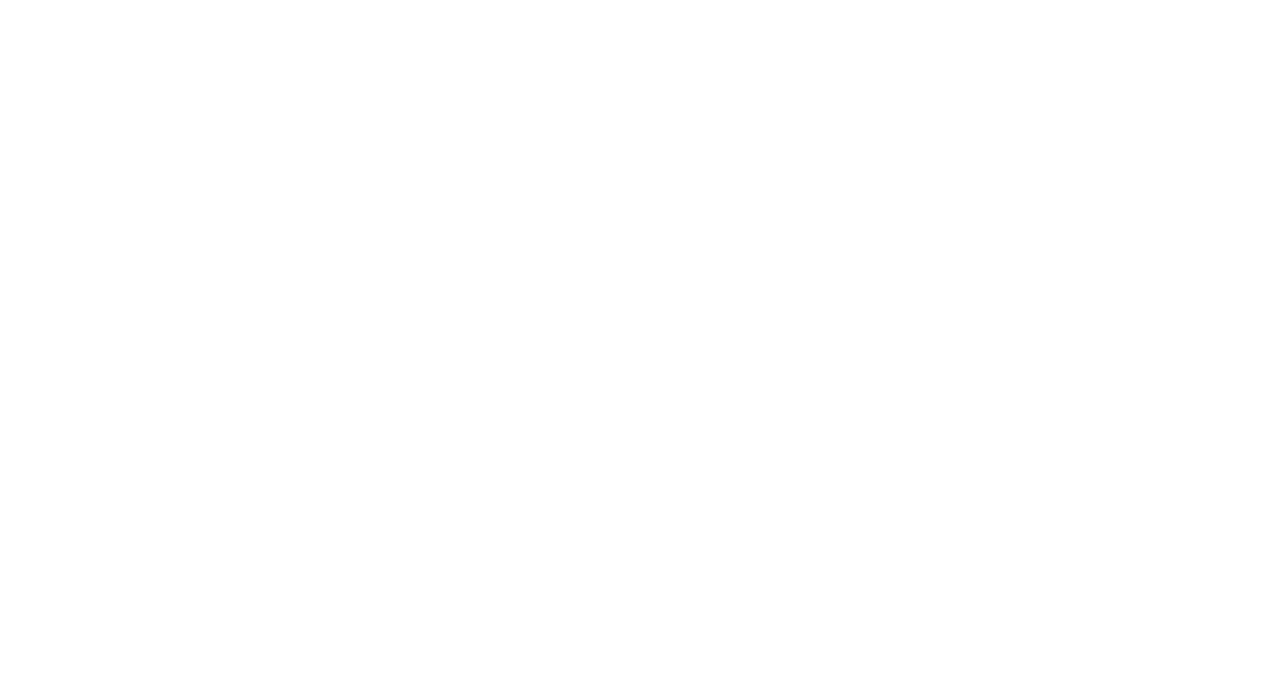

Figure 1: Representative trajectories of air parcels in the no-rad simulation for the dry scenario. Dehydrated and hydrated air parcels are shown respectively in red and blue. The cloud is shaded in yellow. Circle markers appear at the locations and times where/when the air parcels enter the cloudy region. Circle markers are replaced by square markers when the air parcels exit the cloud. 


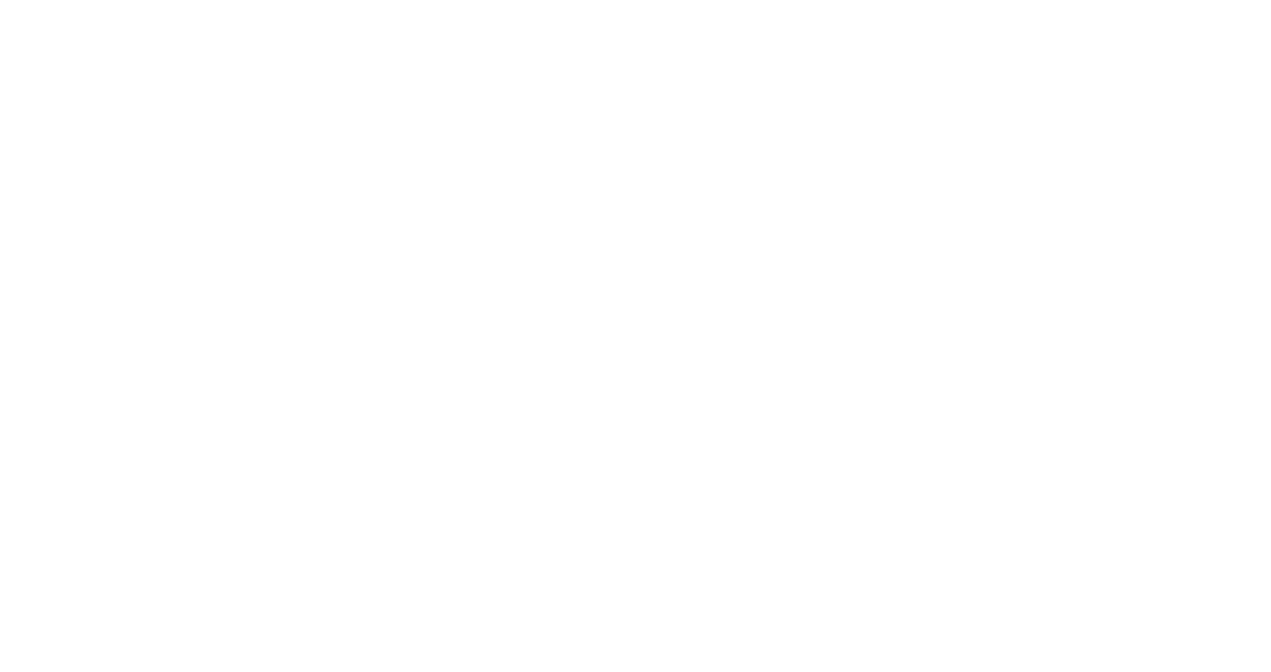

Figure 2: Same as in Fig. 1 but for the all-phys simulation in the dry scenario. 


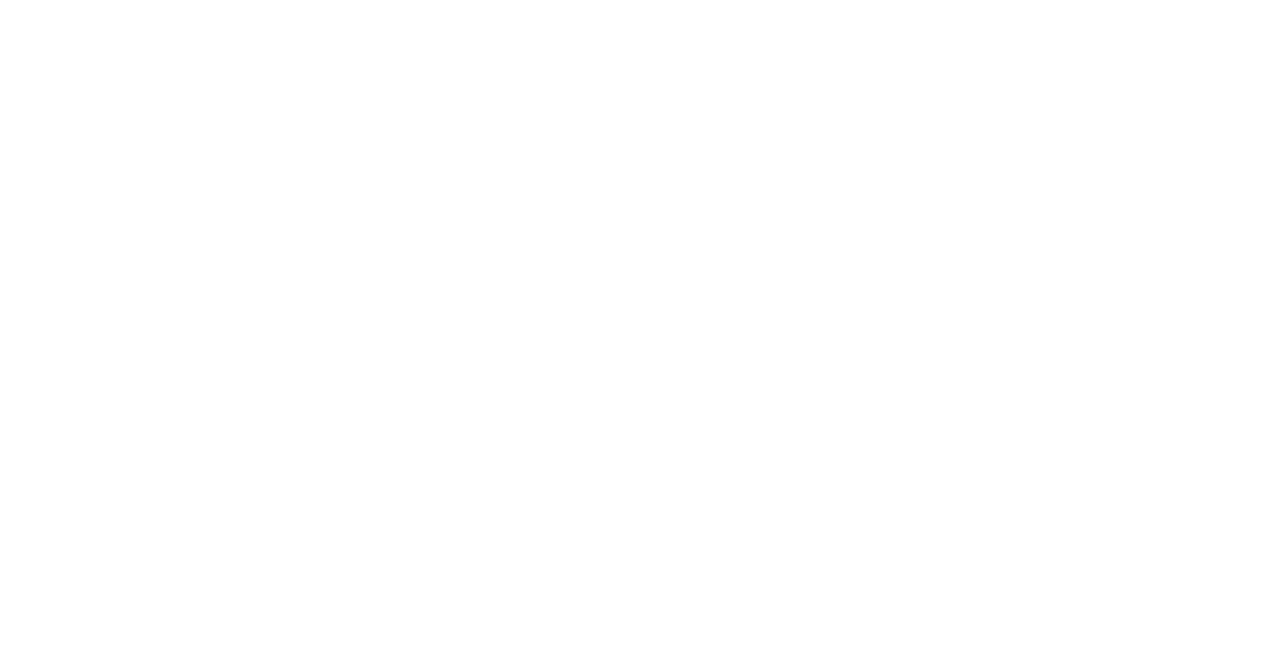

Figure 3: Same as in Fig. 1 but for the no-rad simulation in the moist scenario. 


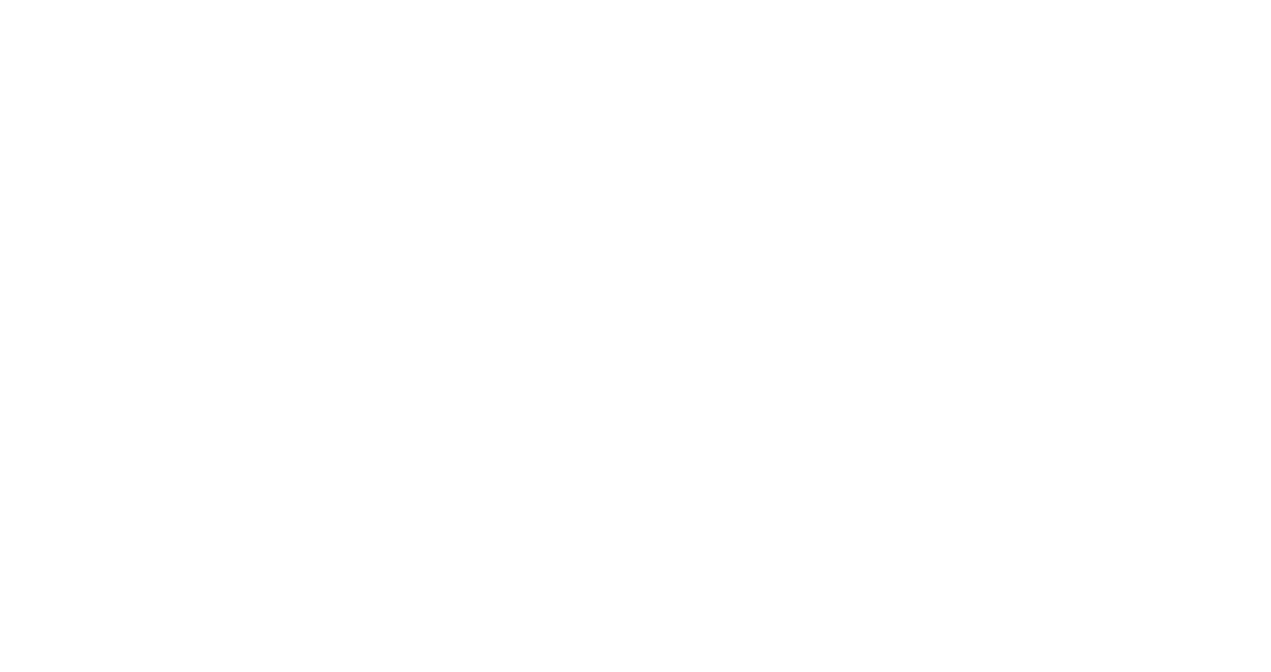

Figure 4: Same as in Fig. 1 but for the all-phys simulation in the moist scenario. 